\title{
Bioactivity evaluations of leaf extract fractions from young barley grass and correlation with their phytochemical profiles
}

Mamata Panthi ${ }^{1 \dagger}$, Romit Kumar Subba ${ }^{1,2 \dagger}$, Bechan Raut $^{1}$, Dharma Prasad Khanal ${ }^{1}$ and Niranjan Koirala ${ }^{2^{*}}$ (D)

\begin{abstract}
Background: The pressed juice of Barley Grass (BG) has become very popular among people for various assumed benefits along with many testimonies of people who have been healed from various ailments such as anemia, cancer, Gl problems by consuming BG. The aim of our research was to validate the claims of its medicinal values such as chemo-protective action, high anti-oxidants, RBC membrane stabilization activity, and toxicity level.
\end{abstract}

Methods: Extracts of hexane, ethyl acetate and methanol were quantitatively estimated for total phenolic contents (TPC) and total flavonoid contents (TFC). The same extracts were assessed for their antioxidative potentials with the use of DPPH free radical scavenging assay followed by determination of HRBC membrane stabilization method, Brine Shrimp Lethality Assay (BSLA) and GC-MS analysis.

Results: All the extracts showed high TPC and TFC along with the stronger correlation with the antioxidant activity of the extracts suggesting phenolics and flavonoids contents of the extract might be attributed to showing antioxidant activity. The methanolic and ethyl acetate extracts of the plant also showed remarkable antiinflammatory activity where methanolic extracts had the lowest EC50. During Brine Shrimp Lethality Assay, all extracts of BG were found to be bioactive and the degree of lethality was found to be concentration dependent. The GC-MS analysis of the methanolic extract of BG revealed 23 compounds which are reported to possess different biological activities.

Conclusion: The study reveals the strong antioxidant and RBC membrane stabilization activity of BG. The Brine Shrimp Lethality Assay found extracts to be bioactive suggesting extracts as a promising candidate for plantderived anti-tumor compounds. Further, studies are needed to validate the data on cancer cell lines.

Keywords: Barley grass, Total phenolic content, Total flavonoid content, Anti-oxidant activity, RBC membrane stabilization activity, Brine shrimp, GC-MS

\footnotetext{
* Correspondence: koirala.biochem@gmail.com

${ }^{\dagger}$ Mamata Panthi and Romit Kumar Subba contributed equally to this work.

${ }^{2}$ Department of Natural Products Research, Dr. Koirala Research Institute for Biotechnology and Biodiversity, Kathmandu, Nepal

Full list of author information is available at the end of the article
}

C C The Author(s). 2020 Open Access This article is licensed under a Creative Commons Attribution 4.0 International License, which permits use, sharing, adaptation, distribution and reproduction in any medium or format, as long as you give appropriate credit to the original author(s) and the source, provide a link to the Creative Commons licence, and indicate if changes were made. The images or other third party material in this article are included in the article's Creative Commons licence, unless indicated otherwise in a credit line to the material. If material is not included in the article's Creative Commons licence and your intended use is not permitted by statutory regulation or exceeds the permitted use, you will need to obtain permission directly from the copyright holder. To view a copy of this licence, visit http://creativecommons.org/licenses/by/4.0/ The Creative Commons Public Domain Dedication waiver (http://creativecommons.org/publicdomain/zero/1.0/) applies to the data made available in this article, unless otherwise stated in a credit line to the data. 


\section{Background}

Oxidative stress is the disturbance in the balance between the production of reactive oxygen species, ROS (free radicals) and antioxidant defenses [1]. ROS might be involved as initiators and mediators in several disease such as heart diseases, endothelial dysfunction, atherosclerosis and other cardiovascular disorders, inflammation, brain degenerative impairments, diabetes and eye disease [2]. Humans are in continuous exposure to free radicals produced from exposure of cigarette smoking, alcohol, radiation, or environmental toxins. A biological antioxidant has been defined as any substance that is present at low concentrations compared to an oxidizable substrate and significantly delays or prevents the oxidation of that substrate [3]. Various anti-oxidants have found to possess properties such as anti-atherosclerotic, antitumor, anti-mutagenic, anti-carcinogenic to name a few selected ones [4]. However, studies have reported that some of most commonly used synthetic antioxidants such as Tert-butyl hydroxy anisole (BHA), tert-butyl hydroxytoluene (BHT) are tumor promoters and can induce impairment in blood clotting [5], therefore research has been directed towards plant derived natural antioxidants.

Inflammation is a complex process, which is frequently associated with pain and involves occurrences such as: the increase of vascular permeability, increase of protein denaturation and membrane alteration. NSAIDS are widely used for their anti-inflammatory, analgesic and antipyretic activity and are among the most widely used drugs worldwide [6]. However, these are associated with an increased risk of adverse gastrointestinal, renal and cardiovascular effects [6]. Various natural compounds with promising in vitro and in vivo anti-inflammatory activities have been reported in literature which can be used as novel therapeutic approach for treatment of inflammatory conditions [7].

Brine Shrimp Lethality Bioassay (BSLB) can provide an indication of possible cytotoxic principles in plant extract [8]. This assay has been extensively used for different studies such as for preliminary toxicity screening of plant extracts, detection of fungal toxins, plant extract toxicity, heavy metals, cyanobacteria toxins, pesticides, and cytotoxicity testing of dental materials [9]. Studies have found very good relationship between this simple, inexpensive, and bench-top assay and the antitumor potential of the cytotoxic compounds [10]. So, BSLB might be helpful as a preliminary screening in the antitumor drug designing and synthesis expeditions [10].

Barley Grass (BG) is the leaf portion of the Hordeum vulgare L., also known as barley, a member of Poeacea family. Young BG has found to have different nutritional content than of the mature barley grain [11]. The variation in nutritional content of BG may depend on the origin of the plants, soil quality and harvest technique [12]. Barley Grass are rich in dietary minerals such as sodium, magnesium, iron, copper and phosphorus and vitamins such as thiamine, riboflavin, tocopherols and tocotrienols, biotin, folic acid and pantothenic acid [13]. These are found to be richer than those found in some popular vegetables (spinach, tomato, lettuce), fruits (banana) and cow's milk [13].

In Nepal, the pressed juice of BG is very popular among residents as 'Jamara Ko Juice'. Various testimonies of people being healed from various ailments such as anemia, cancer, GI problems by consuming BG can be found in the public. For drinking pressed juice, harvesting is usually performed at 7th day. Barley Grass harvesting can be done when the leaves are 12 to $14 \mathrm{in}$. long to derive the maximum benefits from the grass [11]. Barley Grass are widely accepted as a source of anti-oxidants and various compounds with antioxidant activity have been isolated from young barley [14]. Various human and animal studies have reported its beneficial effects such as antiulcer, antioxidant, hypolipidemic, antidepressant, antidiabetic effects and laxative effect [1519]. Based on the traditional ethnomedicines and existing literatures, BG maximizes the chance of providing novel compounds with promising cytotoxic and anti-oxidant activities. The present study was aimed to evaluate the antioxidant activity, RBC membrane stabilization activity, lethality assay and to evaluate the total phenolic contents of BG.

\section{Methods \\ Chemicals}

Gallic acid (GA), ascorbic acid (AA), DPPH and quercetin were purchased from Hi-Media Lab (Mumbai, India). FC reagent and aluminum chloride $\left(\mathrm{AlCl}_{3}\right)$ were purchased from Thermo Fisher Scientific India Pvt. Ltd. (Mumbai, India). Reference standard Diclofenac was obtained from Lomus Pharmaceuticals Pvt. Ltd. (Kathmandu, Nepal). All other chemicals were of standard analytical grade.

\section{Plant materials}

The barley seeds were procured from the local market and were sown in soil from local nursery with daily watering. The Barley Grass were harvested on 7th day of sowing at the month of July. The samples were authenticated by Ganga Datt Bhatt, Research Officer, National Herbarium and Plant Laboratories (NHPL) (Godawari, Lalitpur, Nepal) Voucher number:217. The voucher specimen of this material has been deposited in National Herbarium and Plant Laboratories (NHPL) (Godawari, Lalitpur, Nepal).

\section{Preparation of the extracts}

The harvested BG were washed well using distilled water and shade dried for 21 days before grinding to fine powder. Three hundred grams of fine powder was subjected to successive maceration starting from hexane to ethyl acetate to methanol, $500 \mathrm{ml}$ each for $48 \mathrm{~h}$ at room temperature (27 \pm $\left.1{ }^{\circ} \mathrm{C}\right)$. The extracts were filtered using a Buckner funnel and Whatman No. 1 filter paper. These extracts were dried in a 
rotary evaporator under reduced pressure until dryness and stored at $4{ }^{\circ} \mathrm{C}$, protected from light and humidity for further analysis.

\section{Determination of Total phenolic content}

The total phenolic content (TPC) of the extracts was estimated by Folin-Ciocalteu reagent (FCR) method [20] with slight modifications. Briefly, $1 \mathrm{ml}$ of various extracts $(1 \mathrm{mg} / \mathrm{ml})$ was mixed with FCR $(5 \mathrm{ml}, 1: 10 \mathrm{v} / \mathrm{v}$ DW) and aq. sodium carbonate $(4 \mathrm{ml}, 7 \%)$ solution. The mixture was then incubated for $30 \mathrm{~min}$ at $40^{\circ} \mathrm{C}$ in a water bath before measuring the absorbance at $760 \mathrm{~nm}$ using Microprocessor UV-Vis spectrophotometer-2371 (Electronics India, Himachal Pradesh, India). The phenolic contents were calculated using a standard curve for gallic acid (GA) (10$200 \mu \mathrm{g} / \mathrm{ml}$ ), and the result was expressed as $\mathrm{mg}$ GAE per gram dry weight of fraction (mg GAE/g). All measurements were performed in triplicates.

\section{Determination of Total flavonoid content}

The total flavonoid content (TFC) was determined by $\mathrm{AlCl}_{3}$ coulometric method [21]. An aliquot of $1 \mathrm{ml}$ of various extracts in methanol was added to $10 \mathrm{ml}$ volumetric flask containing $4 \mathrm{ml}$ of distilled water. At the zero-time, $0.3 \mathrm{ml}, 5 \%$ sodium nitrite was added to the flask. After $5 \mathrm{~min}, 3 \mathrm{ml}$ of $10 \% \mathrm{AlCl}_{3}$ was added to the flask. At $6 \mathrm{~min}, 2 \mathrm{ml}$ of $1 \mathrm{M}$ sodium hydroxide was added to the mixture. Immediately, the total volume of the mixture was made up to $10 \mathrm{ml}$ by the addition of $2.4 \mathrm{ml}$ distilled water and mixed thoroughly. Absorbance of the pink colored mixture was determined at $510 \mathrm{~nm}$ against a blank containing using Microprocessor UV-Vis spectrophotometer-2371 (Electronics India, Himachal Pradesh, India). The flavonoid contents were calculated using a calibration curve prepared for Quercetin standards (10 to $100 \mu \mathrm{g} / \mathrm{ml}$ ) and the result was expressed as $\mathrm{mg}$ of quercetin equivalent/g of extract ( $\mathrm{mg} \mathrm{QE} / \mathrm{g}$ of extract).

\section{Determination of anti-oxidant activity}

The DPPH scavenging activity of different fractions was evaluated according to the method of Brand-Williams et al. [22] $1 \mathrm{~mL}$ of $0.1 \mathrm{mM}$ DPPH solution in methanol was mixed with $1 \mathrm{~mL}$ of each extracts at varying concentrations $(5,10,15,20,25 \mu \mathrm{g} / \mathrm{ml})$. The corresponding blank sample was prepared, and ascorbic acid (AA) was used as reference standard. Mixture of $1 \mathrm{~mL}$ extract and $1 \mathrm{~mL}$ $\mathrm{DPPH}$ solution was used as control. The mixture was shaken well and incubated for $30 \mathrm{~min}$ in the dark. The reaction was carried out in triplicate, and the decrease in absorbance was measured at $517 \mathrm{~nm}$ after incubation using a using Microprocessor UV-Vis spectrophotometer-2371 (Electronics India, Himachal Pradesh, India). The scavenging activity was expressed as IC50 $(\mu \mathrm{g} / \mathrm{mL})$. The \% scavenging was calculated using the formula:

$$
\text { \%Scavenging }=\left[\left(\mathrm{A}_{0}-\mathrm{A} 1\right) / \mathrm{A}_{0}\right] \times 100
$$

Where, $\mathrm{A}_{0}=$ absorbance of the control solution.

$\mathrm{A}_{1}=$ absorbance of extract/standard.

\section{Determination of RBC membrane stabilization activity}

RBC membrane stabilization activity of three different extracts of BG was evaluated by using in vitro human red blood cell stability method. The membrane stabilizing activity of the sample was assessed according to the method described by Shinde et al [23] with slight modifications.

The assay mixture contained $1 \mathrm{ml}$ phosphate buffer [PH 7.4, $0.15 \mathrm{M}], 2 \mathrm{ml}$ hypo saline [0.36\%], $0.5 \mathrm{ml}$ HRBC suspension $[10 \% \mathrm{v} / \mathrm{v}]$ with $0.5 \mathrm{ml}$ of plant extracts and standard drug diclofenac sodium of various concentrations $(10,20,40,80,100 \mu \mathrm{g} / \mathrm{ml})$. The control sample consisted of $0.5 \mathrm{~mL}$ of RBCs mixed with hypotonic-buffered saline alone. The mixture was incubated at $37^{\circ} \mathrm{C}$ for $30 \mathrm{~min}$ and centrifuged at 3000 RCF. The hemoglobin content in the suspension was estimated using Microprocessor UV-Vis spectrophotometer-2371 (Electronics India, Himachal Pradesh, India).

$$
\text { \%Protection }=1-[\mathrm{OD} \text { of Test/OD of Control] X } 100
$$

\section{Determination of toxicity}

The toxic activity of the plant was evaluated using Brine shrimp lethality bioassay (BSLA) method [8] where 6 graded doses (viz $1600 \mu \mathrm{g} / \mathrm{mL}, 800 \mu \mathrm{g} / \mathrm{mL}, 400 \mu \mathrm{g} / \mathrm{mL}$, $200 \mu \mathrm{g} / \mathrm{mL}, 100 \mu \mathrm{g} / \mathrm{mL}$, and $50 \mu \mathrm{g} / \mathrm{mL}$ ) were used. Brine shrimps (Artemia salina Leach) nauplii were used as test organisms. For hatching, eggs were kept in artificial sea salt with a constant oxygen supply for $48 \mathrm{~h}$. The mature nauplii were then used in the experiment. DMSO was used as a solvent and also as a negative control. Vincristine sulfate was used as a reference standard in this case. The numbers of survivors were counted after $24 \mathrm{~h}$. Larvae were considered dead if they did not exhibit any internal or external movement during several seconds of observation. The larvae did not receive food. To ensure that the mortality observed in the bioassay could be attributed to bioactive compounds and not to starvation; we compared the dead larvae in each treatment to the dead larvae in the control.

The median lethal concentration (LC50) of the test samples were calculated using the Probit analysis method described by Finney [24], as the measure of toxicity of the plant extract. 
Mortality $\%=($ No.of dead larvae $/$ Total no.of larvae $) \times 100$.

\section{Gas chromatography-mass spectroscopy analysis}

GC-MS analysis was performed at Nepal Academy of Science \& Technology (Khumaltar, Kathmandu, Nepal). For GC-MS analysis of plant extract, GC-MS QP2010 (Shimadzu, Kyoto, Japan) equipped with RTx-5MS fused silica capillary column of $30 \mathrm{~m}$ length X 0.25 $\mathrm{mm}$ diameter $\mathrm{X} 0.25 \mu \mathrm{m}$ film thickness. Helium (> 99.99\% purity) with $36.2 \mathrm{~cm} / \mathrm{sec}$ linear velocity was employed as carrier gas. The system was programmed with $3.9 \mathrm{ml} / \mathrm{min}$ of total flow rate, $0.95 \mathrm{ml} / \mathrm{min}$ of column flow and $3.0 \mathrm{ml} / \mathrm{min}$ purge flow. The volume of injected sample was $1 \mu \mathrm{l}$. The injector was set in spitless mode having $280^{\circ} \mathrm{C}$ of temperature. Oven temperature started from $100{ }^{\circ} \mathrm{C}$ and increased to $250^{\circ} \mathrm{C}$ at $15^{\circ} \mathrm{C} / \mathrm{min}$ with holding time of $1 \mathrm{~min}$, which afterwards increased to $280{ }^{\circ} \mathrm{C}$ at $30^{\circ} \mathrm{C} / \mathrm{min}$ with holding time of $1 \mathrm{~min}$ and again increased from $280{ }^{\circ} \mathrm{C}$ to $300{ }^{\circ} \mathrm{C}$ at $15^{\circ} \mathrm{C} / \mathrm{min}$ with holding time of $11 \mathrm{~min}$.

The ion source temperature and interface temperature were set to $200{ }^{\circ} \mathrm{C}$ and $280{ }^{\circ} \mathrm{C}$ respectively with solvent cut time of $3.5 \mathrm{~min}$. Total run time was $20 \mathrm{~min}$ with mass range scan of 40 to $500 \mathrm{~m} / \mathrm{z}$. Identification of compounds was performed by comparing their mass spectra with data from NIST08 mass spectral library.

\section{Statistical analysis}

Each sample analysis was performed in triplicate. All results presented are means $( \pm$ SEM) of at least three independent experiments. Statistical analysis, ANOVA with a statistical significance level set at $p<0.05$ with post-hoc Tukey procedure was carried out with SPSS 16 for Windows. Correlations between the total phenolic contents, flavonoid contents and antioxidant capacities were determined using the Pearson correlation.

\section{Results}

\section{Total phenolic content determination}

The total phenolic content of three extracts determined by FCR method were expressed as GAE/g dried extract (Fig. 1). The phenolic content in all extracts ranged from 24.55 to $82.56 \mathrm{mg}$ GAE/g dried extracts representing an approximate three-fold variation (Table 1). Methanolic extract had significantly higher phenolic contents than ethyl acetate and hexane.

\section{Total Phenolic Content}

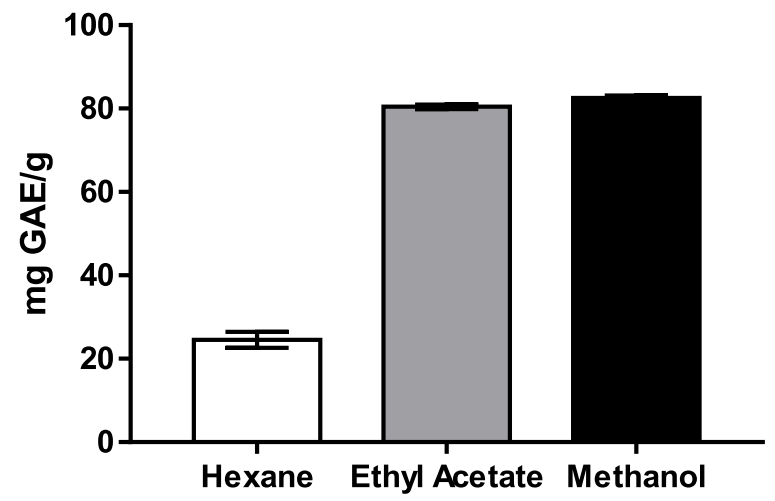

Fig. 1 TPC of various extracts of BG

Total flavonoid content determination

The result of total flavonoid contents of three extracts of barley grass is given in Fig. 2. The total flavonoid contents were reported as QE, ranged from 18.94 to 45.76 mg QE/g dried extracts (Table 1). Methanolic extract had significantly highest flavonoid content followed by ethyl acetate and hexane extracts.

\section{Anti-oxidant activity determination}

The anti-oxidant potential of all extracts were assessed by DPPH free radical scavenging assay. The radical scavenging is one of mechanism of antioxidant activity. The results were expressed in terms of $\mathrm{IC}_{50}$ and is shown in Table 2 . The lower $\mathrm{IC}_{50}$ represents higher scavenging ability. The $\mathrm{IC}_{50}$ of methanolic extract $\left(\mathrm{IC}_{50}=104.9 \mu \mathrm{g} / \mathrm{ml}\right)$ was found to be significantly lower than the ethyl acetate $(455.24 \mu \mathrm{g} /$ $\mathrm{ml})$ and hexane $(659.97 \mu \mathrm{g} / \mathrm{ml})$ extracts. However, the activity of all extracts was found to be less when compared to standard, AA $(22.58 \mu \mathrm{g} / \mathrm{ml})$ (Fig. 3).

\section{Correlation between TPC, TFC and anti-oxidant activity of} the extracts

There was a higher correlation between total flavonoid content (TFC) and DPPH radical scavenging activity $(\mathrm{R}=$ - 0.936). Similarly, the correlation between total phenolic

Table 1 TFC and TPC of various extracts of BG

\begin{tabular}{lll}
\hline Extracts & $\begin{array}{l}\text { TFC }(\mathrm{mg} \mathrm{QE} / \mathrm{g} \\
\text { dried extract) }\end{array}$ & $\begin{array}{l}\text { TPC }(\mathrm{mg} \text { GAE/ g } \\
\text { dried extract) }\end{array}$ \\
\hline Hexane & $18.94 \pm 0.42^{\mathrm{a}}$ & $24.55 \pm 1.94^{\mathrm{a}}$ \\
Ethyl Acetate & $19.07 \pm 0.33^{\mathrm{b}}$ & $80.42 \pm 0.54^{\mathrm{b}}$ \\
Methanol & $45.76 \pm 2.40^{\mathrm{b}}$ & $82.56 \pm 0.59^{\mathrm{b}}$ \\
\hline
\end{tabular}

Values are in Mean \pm SEM $(n=3)$. Values in the same column followed by a different letter are significantly different $(P<0.001)$ 


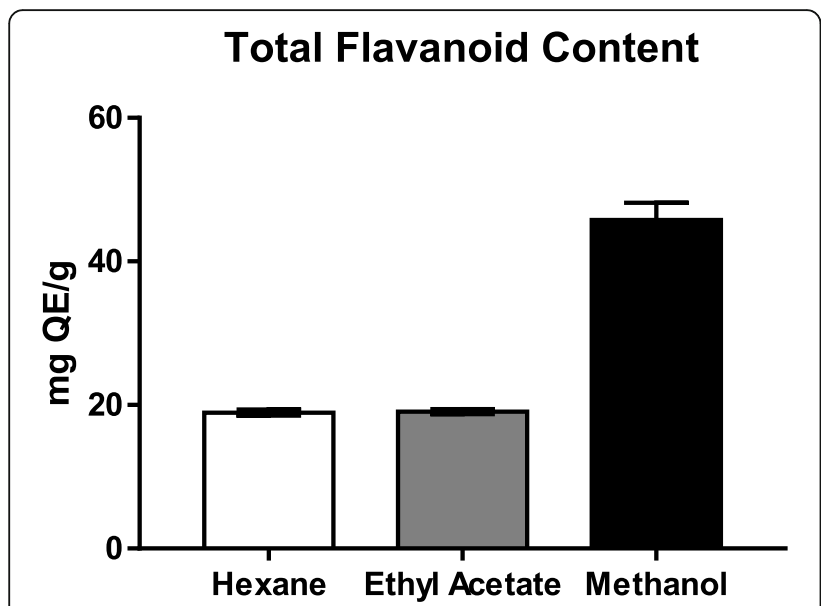

Fig. 2 TFC of various extracts of BG

content $(\mathrm{TPC})$ and DPPH radical scavenging activity $(\mathrm{R}=$ $-0.795)$ was also higher.

\section{RBC membrane stabilization activity determination}

Membrane stabilizing activity was assayed to evaluate the inhibition of hypotonic solution induced lysis of human erythrocyte membrane. The extracts were effective in inhibiting the hypotonicity induced hemolysis at different concentrations. These provides evidence for membrane stabilization as a possible mechanism of their antiinflammatory effect. The EC50 found to be in order of Hexane> Ethyl acetate> Methanol> Diclofenac (Fig. 4; Table 3). Significant differences $(p<0.005)$ was found between $\%$ protection values of different extracts.

\section{Determination of toxicity}

All the extracts were subjected to Brine Shrimp lethality bioassay for possible toxic action. In this study, methanol extract was found to be the most toxic to Brine Shrimp nauplii, with LC50 of $266.49 \mu \mathrm{g} / \mathrm{ml}$ whereas anticancer drug, vincristine sulphate showed LC50 value $1.707 \mu \mathrm{g} / \mathrm{ml}$ (Table 4). The order at which cytotoxic potential of the test samples was as follows:

Table $2 \mid C_{50}$ Values of different extracts and ascorbic acid

\begin{tabular}{llll}
\hline Extracts & $\begin{array}{l}\text { Regression } \\
\text { Equation }\end{array}$ & $\begin{array}{l}\text { Correlation } \\
\text { Coefficient }\left(\mathrm{R}^{2}\right)\end{array}$ & $\mathrm{I} \mathrm{C}_{50}(\mu \mathrm{g} / \mathrm{ml})$ \\
\hline Hexane & $\mathrm{y}=0.0758 \mathrm{x}-0.0257$ & 0.9651 & 659.97 \\
Ethyl Acetate & $\mathrm{y}=0.1111 \mathrm{x}-0.5772$ & 0.9347 & 455.24 \\
Methanol & $\mathrm{y}=0.5009 \mathrm{x}-2.5436$ & 0.9777 & 104.90 \\
AA & $y=2.7378 x-11.819$ & 0.9838 & 22.58 \\
\hline
\end{tabular}

AA Ascorbic acid
Vincristine sulphate> Methanol> Hexane> Ethyl acetate.

\section{Gas chromatography-mass spectroscopy analysis}

The GC-MS analysis of phytoconstituents in methanolic extract of barley grass revealed the presence of twenty-three major phytoconstituents (Fig. 5; Table 5). The major phytocomponents reported are Indolizine (21.78\%), Octadecyl trifluoroacetate (15.85\%), Palmitic acid (8.15\%),1-Hexadecyne (6.98\%), 1H-Indole,5-methyl- (4.46\%), 9,12,15-Octadecatrienoic acid (1.64\%), Phytol (1.61\%) and Squalene (0.82\%) (Figure S1).

\section{Discussion}

Phenolic compounds are a group of chemical compounds that are widely distributed in nature. Phenolic compounds are nutritionally important and the interest in these compounds are increasing for their various bioactivities such as antioxidant, anti-aging, antiinflammatory and anti-proliferative activities [25]. We found methanol to be significantly more efficient to extract polyphenolic compounds compared to ethyl acetate and hexane extracts of BG. These findings are in support of higher solubility of phenols in polar solvents providing high concentration of these compounds in the extracts obtained using polar solvents for the extraction [26]. Different phenolic compounds including flavones (e.g. major leaf antioxidants, such as saponarin, lutonarin, and 2-O-glucosylvitexin), leucoanthocyanidins, catechins, and coumarins have been found in young barley extracts [27]. The TPC contents in BG juice were significantly higher than wheatgrass and rice juices reported by Wangcharoen et al. [28]. However, phenolic contents in BG can be affected by different factors such as light quality, cultivars and harvesting times $[29,30]$.

Flavonoids are some of the most common phenolics, widely distributed in the plant tissues. Reviews on flavonoids have found it as a possible cancerpreventive agent [31]. Quercetin, a flavonoid, can be considered as the prototype of a naturally occurring chemo-preventive agent [32]. In this study, the total flavonoids contents of the different organic crude plant extracts were determined as quercetin equivalents by a modified aluminum chloride coulometric method [21]. Methanolic extract found to have significantly higher flavonoid content than ethyl acetate and hexane extract.

The antioxidant activity was evaluated by the capacity of antioxidant compound to reduce the DPPH radical as indicated by the decrease in its absorbance at $517 \mathrm{~nm}$ until the reaction reached a plateau. Significant differences $(p<0.0383)$ was obtained between antioxidant activity of the different extracts of BG. 


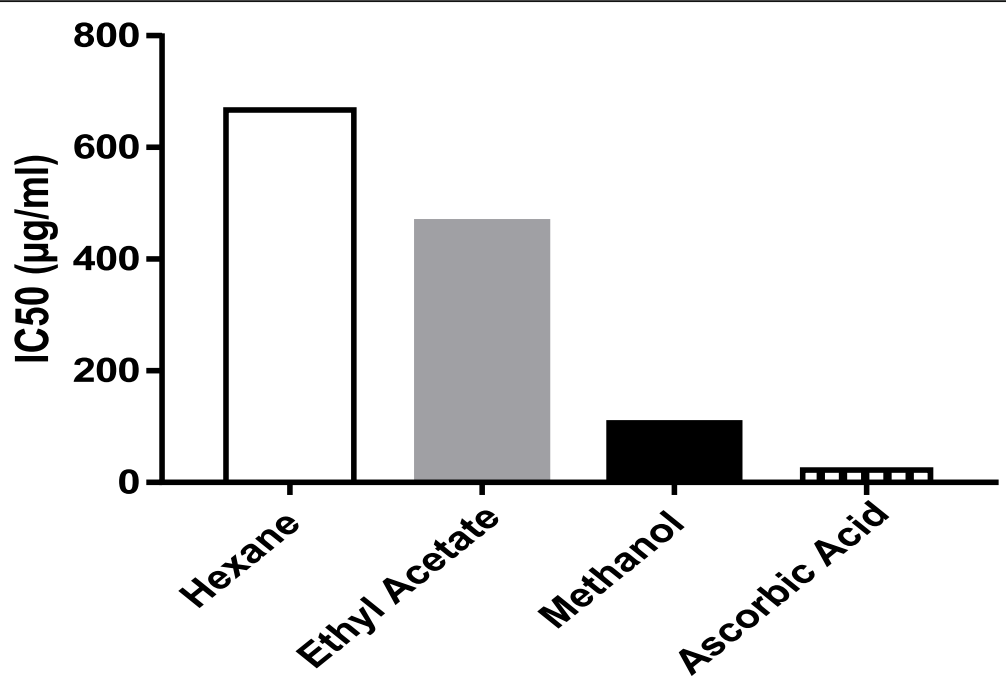

Fig. $3 \mid C_{50}$ values of various extracts and ascorbic acid

The methanolic extracts of BG had lowest IC50 value and thus with the highest antioxidant activity followed by ethyl acetate and hexane. The IC50 value of methanolic extract was found to be $104.41 \mu \mathrm{g} / \mathrm{ml}$ which is similar to the IC50 found by the Nepal et al. for $80 \%$ methanolic extract [33]. The differences of antioxidant activity between various extracts could be due to the difference in total amount of phenolics and flavonoids as phenolic and flavonoids are reported to have anti-oxidant activity [34] [35]. Pearson Correlation analysis were used to determine the relation between these parameters. There was a higher correlation between TFC and DPPH radical

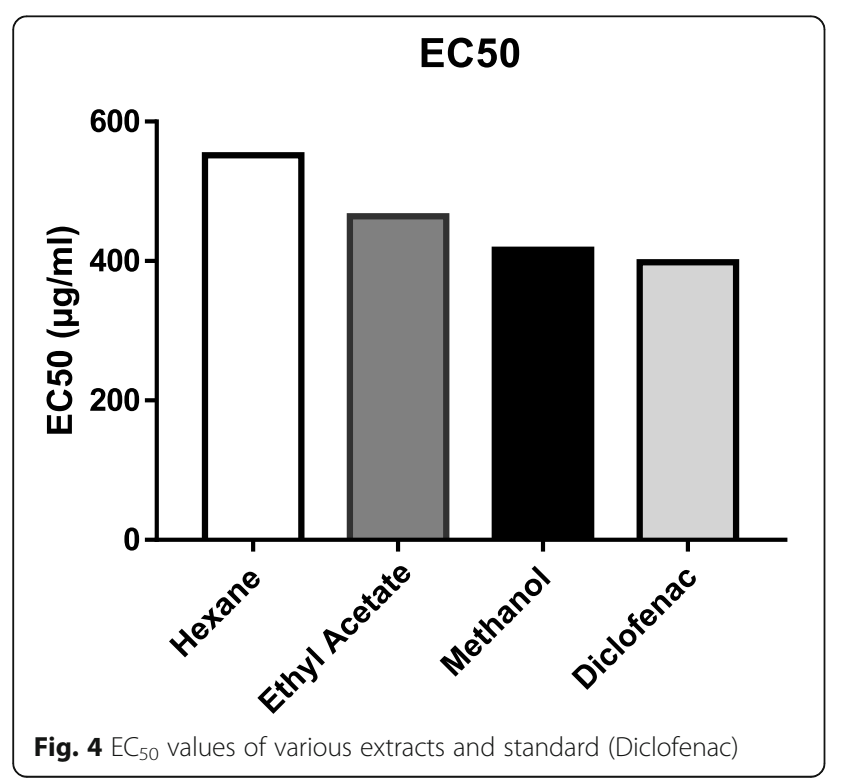

scavenging activity $(R=-0.936)$, and the correlation between TPC and DPPH radical scavenging activity $(R=-0.795)$ was also found to be high suggesting phenolics and flavonoids might have attributed to show anti-oxidant activity in BG. The correlation was found to be negative as increase in TPC and TFC caused increase in antioxidant activities, which was exposed by lower IC50 of DPPH scavenging activity. Previous studies have also showed that total phenolic contents of culinary plants were significantly correlated $(p<0.05)$ to their antioxidant activities [36].

In $\mathrm{RBC}$ membrane stabilization activity test, all extracts were effective in inhibiting the hypotonicity induced hemolysis at different concentrations. The methanolic extract had lowest EC50 than ethyl acetate and hexane. RBC membrane stabilization activity test can be related to the anti-inflammatory activity of the BG. This is by far the first reported study on HRBC membrane stabilization study on BG. The GC-MS analysis of methanolic extract reported several phytoconstituents with anti-inflammatory activity such as Indolizine [37], 9,12,15-Octadecatrienoic acid [38], Phytol [39], Squalene [40]. The presence of such compounds could be the reason for the activity of extracts.

Table $3 \mathrm{EC}_{50}$ values of different extracts and diclofenac

\begin{tabular}{ll}
\hline Extracts & $\mathrm{EC}_{50}(\mu \mathrm{g} / \mathrm{ml})$ \\
\hline Hexane & 551.69 \\
Ethyl Acetate & 464.40 \\
Methanol & 416.15 \\
Diclofenac & 398.31 \\
\hline
\end{tabular}


Table $4 L C_{50}$ of the different extracts Brine shrimp lethality bioassay

\begin{tabular}{|c|c|c|c|}
\hline Test Sample & Concentration $(\mu \mathrm{g} / \mathrm{ml})$ & \%Mortality & $\mathrm{LC}_{50}(\mu \mathrm{g} / \mathrm{ml})$ \\
\hline \multirow[t]{6}{*}{ Hexane } & 50 & 20 & 290.72 \\
\hline & 100 & 30 & \\
\hline & 200 & 50 & \\
\hline & 400 & 60 & \\
\hline & 800 & 70 & \\
\hline & 1600 & 90 & \\
\hline \multirow[t]{6}{*}{ Ethyl Acetate } & 50 & 10 & 367.91 \\
\hline & 100 & 20 & \\
\hline & 200 & 50 & \\
\hline & 400 & 50 & \\
\hline & 800 & 70 & \\
\hline & 1600 & 80 & \\
\hline \multirow[t]{6}{*}{ Methanol } & 50 & 0 & 266.49 \\
\hline & 100 & 30 & \\
\hline & 200 & 50 & \\
\hline & 400 & 60 & \\
\hline & 800 & 80 & \\
\hline & 1600 & 90 & \\
\hline \multirow[t]{5}{*}{ VS } & 0.25 & 30 & 1.71 \\
\hline & 0.5 & 40 & \\
\hline & 1 & 50 & \\
\hline & 5 & 90 & \\
\hline & 10 & 100 & \\
\hline
\end{tabular}

VS Vincristine Sulphate

The GC-MS analysis of methanolic extract of BG revealed 23 compounds. These compounds are reported to possess different activities. For ex, Indolizine has anti-inflammatory properties [37]. Phytol is a diterpene which is reported to have anti-inflammatory and cancer preventive properties [39]. Fatty acids like 13-docosenic acid and 9,12,15-Octadecatrienoic acid are reported to be in BG. They have cancer preventive, nematicide, anti-arthritic, anti andrigenic, antiinfammatory and hypocholesterolemic properties [38]. Cyclotetracosane has anti-diabetic or alpha amylase activity [41]. Squalene possess anti-bacterial, antioxidant, cancer preventive, anti-tumor and lipoxygenase inhibitor [40]. Hexadecen-1-ol, trans 9 possess anti-oxidant and anti-tumor [42].

The degree of lethality shown by BG was found to be directly proportional to the concentration of the extractives ranging from the lowest concentration $(50 \mu \mathrm{g} / \mathrm{ml})$ to the highest concentration $(1600 \mu \mathrm{g} / \mathrm{ml})$. This concentration dependent increment in percent mortality of Brine Shrimp nauplii produced by the BG may indicates the presence of cytotoxic principles in these extracts.

Methanol extracts had the lowest LD50 as $266.49 \mu \mathrm{g} / \mathrm{ml}$ followed by ethyl acetate, $367.91 \mu \mathrm{g} / \mathrm{ml}$ and hexane, $290.72 \mu \mathrm{g} / \mathrm{ml}$. In toxicity evaluation of plant extracts by Brine shrimp lethality bioassay LD50 values lower than $1000 \mu \mathrm{g} / \mathrm{ml}$ are considered bioactive [8]. Thus, all extracts of BG are found to be bioactive. The brine shrimp assay is significantly correlated with in vitro growth inhibition of human solid tumor cell lines demonstrated by the national Cancer Institute (NCI, USA) and it can show the value of this bioassay as a pre-screening tool for antitumor drug research [43]. Therefore, these extracts can be regarded as promising candidate for plant derived anti-tumor compounds. A study on a barley grass supplement named as Herb-All Barley Powder found the LD50 to be $448.42 \mathrm{ppm}$ in a similar setting [44].

\section{Conclusions}

This study showed the importance of BG and its possible health benefits. Barley Grass could be considered as functional drinks with antioxidant potential

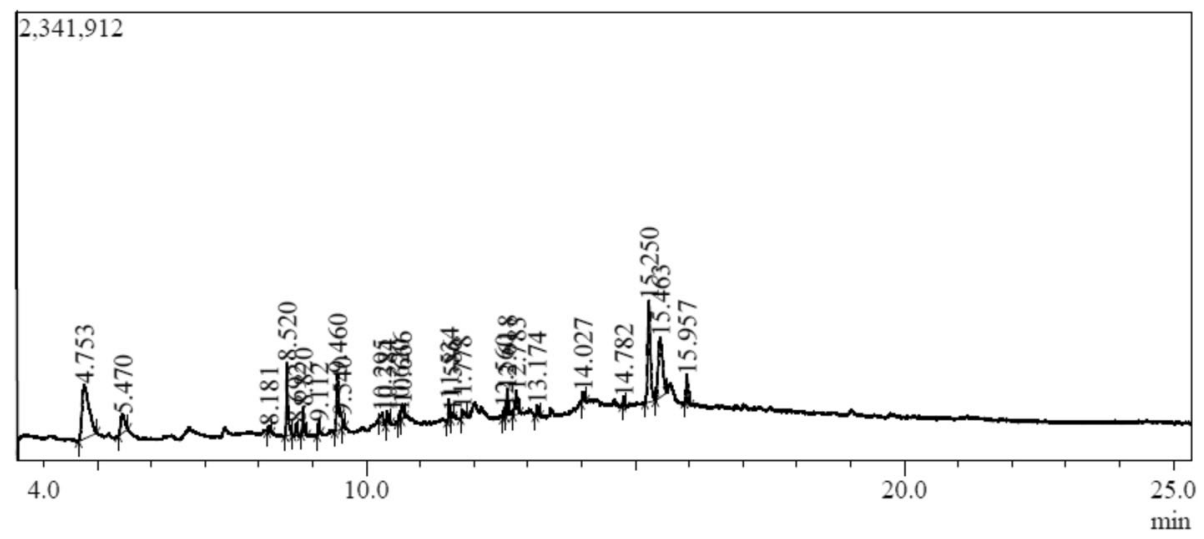

Fig. 5 GCMS chromatogram of methanolic extracts of BG 
Table 5 Composition of methanolic extract of BG

\begin{tabular}{|c|c|c|c|c|}
\hline Peak\# & R. T & Area\% & Name & Mol. Wt. \\
\hline 1 & 4.753 & 21.78 & Indolizine & 117 \\
\hline 2 & 5.470 & 4.46 & 1H-Indole, 5-methyl- & 131 \\
\hline 3 & 8.181 & 0.53 & Hexadecen-1-ol, trans-9- & 240 \\
\hline 4 & 8.520 & 10.35 & 1-Hexadecyne & 222 \\
\hline 5 & 9.112 & 0.94 & Hexadecanoic acid, methyl ester & 270 \\
\hline 6 & 9.460 & 8.15 & n-Hexadecanoic acid & 256 \\
\hline 7 & 9.540 & 0.93 & 1-Tridecyn-4-ol & 196 \\
\hline 8 & 10.295 & 1.65 & 11,14,17-Eicosatrienoic acid, methyl ester & 320 \\
\hline 9 & 10.384 & 1.61 & Phytol & 296 \\
\hline 10 & 10.620 & 1.26 & 5-Tetradecyne & 194 \\
\hline 11 & 10.666 & 1.64 & 9,12,15-Octadecatrienoic acid, (Z,Z,Z)- & 278 \\
\hline 12 & 11.534 & 1.59 & Octanoic acid, 2-dimethylaminoethyl ester & 215 \\
\hline 13 & 11.586 & 0.40 & Oxalic acid, propyl tridecyl ester & 314 \\
\hline 14 & 11.778 & 1.24 & (E)-13-Docosenoic acid & 338 \\
\hline 15 & 12.560 & 0.77 & 3-Cyclopentylpropionic acid, 2-dimethylami & 213 \\
\hline 16 & 12.618 & 2.11 & 3-Cyclopentylpropionic acid, 2-dimethylami & 213 \\
\hline 17 & 12.783 & 3.20 & Hexadecen-1-ol, trans-9- & 240 \\
\hline 18 & 13.174 & 0.99 & Diisooctyl phthalate & 390 \\
\hline 19 & 14.027 & 1.12 & Heptadecyl heptafluorobutyrate & 452 \\
\hline 20 & 14.782 & 0.82 & Squalene & 410 \\
\hline 21 & 15.250 & 15.85 & Octadecyl trifluoroacetate & 366 \\
\hline 22 & 15.463 & 15.71 & 4-Oxo-2-phenyl-1,4-dihydroquinoline-3-carbonitrile & 246 \\
\hline 23 & 15.957 & 2.92 & 1-Heptadecanol, acetate & 298 \\
\hline
\end{tabular}

R.T Retention Time (minutes)

because of their higher phenolic content and flavonoid content. There was a strong correlation of TFC, TPC and anti-oxidant activity of the extracts which suggests the flavonoids and phenolics might have shown anti-oxidant activity in these extracts. Presence of anti-inflammatory compounds and because of significant RBC membrane stabilization activity, BG can also be regarded as functional drinks with antiinflammatory potential. All extracts of BG had shown significant bioactivity towards brine shrimp which have good correlation with tumor cell lines suggesting these extracts to be as promising candidate for plant derived anti-tumor compounds. Thus, further studies are needed to validate the data on cancer cell lines.

\section{Supplementary information}

Supplementary information accompanies this paper at https://doi.org/10 1186/s12906-020-2862-4.

Additional file 1 : Figure S1. Chromatogram of various compounds in methanolic extract of BG based on GC-MS profile of Fig. 6. Table S1. Absorbance values of extracts in TPC determination. Table S2. Absorbance values of extracts in TFC determination. Table S3. Absorbance values of extracts and ascorbic acid in anti-oxidant activity determination. Table
S4. Absorbance values of extracts and diclofenac in anti-Inflammatory activity determination. Table S5. Dead brine shrimp counts of extracts in Brine shrimp lethality assay.

\section{Abbreviations}

$\mathrm{AlCl}_{3}$ : Aluminum chloride; BG: Barley grass; BSLA: Brine shrimp lethality assay; DMSO: Dimethyl sulfoxide; DPPH 1: 1 -diphenyl-2-picryhydrazyl; FCR: Folinciocalteu reagent; GAE: Gallic acid equivalent; GAE: Gallic Acid equivalents; GC-MS: Gas chromatography mass spectroscopy; HRBC: Human red blood cell; QE: Quercetin equivalent; TFC: Total flavonoids content; TPC: Total phenolics content

\section{Acknowledgments}

The authors are thankful to the management of Manmohan Memorial Institute of Health Sciences, Kathmandu and Dr. Koirala Research Institute for Biotechnology and Biodiversity, Kathmandu, Nepal for rendering necessary facilities to complete this work.

\section{Authors' contribution}

MP and RKS made significant contribution to acquisition of data, analysis, drafting of the manuscript. BR and DPK has made substantial contribution to conception, design and interpretation of data. NK supervised the research works, participated in revising, editing and the manuscript submission. All authors read and approved the final manuscript.

\section{Funding}

Manmohan Memorial Institute of Health Sciences, Kathmandu, Nepal in associations with Dr. Koirala Research Institute for Biotechnology and 
Biodiversity, Kathmandu, Nepal funded this research by providing the facilities and chemicals to carry out this study.

\section{Availability of data and materials}

The datasets used and/or analyzed during the current study are available from the corresponding author on reasonable request.

\section{Ethics approval and consent to participate}

Not applicable.

\section{Consent for publication}

Not applicable.

\section{Competing interests}

The authors declare that they have no competing interests.

\section{Author details}

${ }^{1}$ Department of Pharmacy, Manmohan Institute of Health Sciences, Tribhuvan University, Kathmandu, Nepal. ²Department of Natural Products Research, Dr. Koirala Research Institute for Biotechnology and Biodiversity, Kathmandu, Nepal.

Received: 21 April 2019 Accepted: 20 February 2020

Published online: 28 February 2020

\section{References}

1. Betteridge DJ. What is oxidative stress? Metabolism. 2000;49(2, Supplement 1):3-8

2. Kohen R, Nyska A. Invited review: oxidation of biological systems: oxidative stress phenomena, Antioxidants, Redox Reactions, and Methods for Their Quantification. Toxicol Pathol. 2002;30(6):620-50.

3. Barry Halliwell JMCG. Free Radicals in Biology and Medicine. 3rd ed. Oxford: Oxford University Press; 1999.

4. Uttara B, et al. Oxidative stress and neurodegenerative diseases: a review of upstream and downstream antioxidant therapeutic options. Curr Neuropharmacol. 2009;7(1):65-74

5. Kahl R, Kappus H. Toxicology of the synthetic antioxidants BHA and BHT in comparison with the natural antioxidant vitamin E. Z Lebensm Unters Forsch. 1993;196(4):329-38

6. Bacchi S, et al. Clinical pharmacology of non-steroidal anti-inflammatory drugs: a review. Antiinflamm Antiallergy Agents Med Chem. 2012;11(1):52-64

7. Maione $F$, et al. Medicinal plants with anti-inflammatory activities. Nat Prod Res. 2016;30(12):1343-52.

8. Meyer BN, et al. Brine shrimp: a convenient general bioassay for active plant constituents. Planta Med. 1982;45(1):31-4

9. Carballo $\mathrm{J}$, et al. A comparison between two brine shrimp assays to detect in vitrocytotoxicity in marine natural products. BMC Biotechnol. 2002:2(1):17.

10. Nazir S, et al. Brine shrimp lethality assay 'an effective prescreen': microwave-assisted synthesis, BSL toxicity and 3DQSAR studies-based designing, docking and antitumor evaluation of potent chalcones. Pharm Biol. 2013:51(9):1091-103.

11. Hagiwra $Y$, Hagiwara $H$, UH. Physiologically active substances in young green barley leaf extract. Nippon Shokuhin Kagaku Kogaku Kaishi. 2001; 48(10):712-25.

12. Droushiotis DN. The effect of variety and harvesting stage on forage production of barley in a low-rainfall environment. J Agric Sci. 2009;102(2): 289-93.

13. Hagiwara Y, Cichoke A. Barley leaves extract for everlasting health. Green Foods Corp Japan Pharm Dev. 1998;7(10):15.

14. Osawa T, et al. A novel antioxidant isolated from young green barley leaves J Agric Food Chem. 1992;40(7):1135-8.

15. Ohtake $H_{\text {, et }}$ al. Studies on the constituents of green juice from young barley leaves. Effect on dietarily induced hypercholesterolemia in rats. Yakugaku Zasshi. 1985;105(11):1052-7.

16. Yu YM, et al. Antioxidative and hypolipidemic effects of barley leaf essence in a rabbit model of atherosclerosis. Jpn J Pharmacol. 2002;89(2):142-8.

17. Yamaura K, et al. Antidepressant-like effects of young green barley leaf (Hordeum vulgare L.) in the mouse forced swimming test. Pharm Res. 2012; 4(1):22-6.

18. Yu YM, et al. Effects of young barley leaf extract and antioxidative vitamins on LDL oxidation and free radical scavenging activities in type 2 diabetes. Diabetes Metab. 2002;28(2):107-14.
19. Ikeguchi $M$, et al. Effects of young barley leaf powder on gastrointestina functions in rats and its efficacy-related physicochemical properties. Evid Based Complement Alternat Med. 2014;2014:974840.

20. Singleton VL, Rossi JA. Colorimetry of Total Phenolics with PhosphomolybdicPhosphotungstic acid reagents. Am J Enol Vitic. 1965;16(3):144-58.

21. Zhishen J, Mengcheng $T$, Jianming $W$. The determination of flavonoid contents in mulberry and their scavenging effects on superoxide radicals. Food Chem. 1999;64(4):555-9.

22. Brand-Williams W, Cuvelier ME, Berset C. Use of a free radical method to evaluate antioxidant activity. LWT Food Sci Technol. 1995;28(1):25-30.

23. Shinde $U$, et al. Membrane stabilizing activity - a possible mechanism of action for the anti-inflammatory activity of Cedrus deodara wood oil. Fitoterapia. 1999;70(3):251-7.

24. Finney DJ, Tattersfield F. Probit analysis. Cambridge: Cambridge University Press; 1952.

25. Koirala $\mathrm{N}$, et al. Metabolic engineering of Escherichia coli for the production of isoflavonoid-4'-O-methoxides and their biological activities. Biotechnol Appl Biochem. 2019;66(4):484-93.

26. Haminiuk CW, et al. Extraction and quantification of phenolic acids and flavonols from Eugenia pyriformis using different solvents. J Food Sci Technol. 2014;51(10):2862-6.

27. Czerwonka A, et al. Evaluation of anticancer activity of water and juice extracts of young Hordeum vulgare in human cancer cell lines HT-29 and A549. Ann Agric Environ Med. 2017:24(2):345-9.

28. Wangcharoen W, Phimphilai S. Chlorophyll and total phenolic contents, antioxidant activities and consumer acceptance test of processed grass drinks. J Food Sci Technol. 2016;53(12):4135-40.

29. Urbonavičiūte $\mathrm{A}$, et al. The effect of light quality on the antioxidative properties of green barely leaves. Sodininkystè ir Darzininkyste. 2009;28:153-61.

30. Park MJ, Seo WD, Kang Y-H. The antioxidant properties of four Korean barley cultivars at different harvest times and profiling of major metabolites. J Agric Sci. 2015;7(10):94

31. Koirala N, Thuan NH, Ghimire GP, Thang DV, Sohng JK. Methylation of flavonoids: chemical structures, bioactivities, progress and perspectives for biotechnological production. Enzym Microb Technol. 2016;86:103-16.

32. Russo $M$, et al. The flavonoid quercetin in disease prevention and therapy: facts and fancies. Biochem Pharmacol. 2012:83(1):6-15.

33. Nepal P, et al. Comparative Antioxidant, Antimicrobial and Phytochemical Assesments of Leaves of Desmostachya bipinnata L. Stapf, Hordeum vulgare L. and Drepanostachyum falcatum (Nees) Keng f. Nepal J Biotechnol. 2018; 6(1):1-10.

34. Shahidi F, Ambigaipalan P. Phenolics and polyphenolics in foods, beverages and spices: antioxidant activity and health effects-a review. J Funct Foods. 2015;18:820-97.

35. Pietta P-G. Flavonoids as antioxidants. J Nat Prod. 2000;63(7):1035-42.

36. Wangcharoen W, Morasuk W. Antioxidant capacity and phenolic content of some Thai culinary plants. Maejo Int J Sci Technol. 2007;1(2):100-6.

37. Shrivastava SK, et al. Design, synthesis, and biological evaluation of some nove indolizine derivatives as dual cyclooxygenase and lipoxygenase inhibitor for anti-inflammatory activity. Bioorg Med Chem. 2017;25(16):4424-32.

38. Erdinest $\mathrm{N}$, et al. Anti-inflammatory effects of alpha linolenic acid on human corneal epithelial cells. Invest Ophthalmol Vis Sci. 2012;53(8):4396-406.

39. Gnanavel V, Saral AM. GC-MS analysis of petroleum ether and ethanol leaf extracts from Abrus precatorius Linn; 2013.

40. Agnel R, Mohan V. GC-MS analyses of bioactive compounds present in the whole plant of Andrographis echioides (I) nees. Eur J Biomed Pharm Sci. 2014:1(3):443-52.

41. Tundis R, et al. Studies on the potential antioxidant properties of Senecio stabianus Lacaita (Asteraceae) and its inhibitory activity against carbohydrate-hydrolysing enzymes. Nat Prod Res. 2012;26(5):393-404.

42. Huang F-C, et al. Substrate promiscuity of RdCCD1, a carotenoid cleavage oxygenase from Rosa damascena. Phytochemistry. 2009;70(4):457-64.

43. Anderson JE, et al. A blind comparison of simple bench-top bioassays and human tumour cell cytotoxicities as antitumor prescreens. Phytochem Anal. 1991;2(3):107-11.

44. Zaman MAH, et al. Antimitotic activity and cytotoxicity assessment of barley grass food supplement. Int J Humaniti Soc Sci. 2018;10(2):11-21.

\section{Publisher's Note}

Springer Nature remains neutral with regard to jurisdictional claims in published maps and institutional affiliations. 